\title{
Establishing activity centers for elderly people in metropolitan areas of Vietnam: preference and willingness-to-pay
}

This article was published in the following Dove Press journal: Journal of Multidisciplinary Healthcare

\author{
Thu Thi Hoai Nguyen $\mathbb{D}^{1-3}$ \\ Thanh Xuan Nguyen ${ }^{1,3}$ \\ Thang Pham ${ }^{1,3}$ \\ Cuong Tat Nguyen ${ }^{4}$ \\ Giang Thu $\mathrm{Vu}^{5}$ \\ Long Hoang Nguyen (iD) 6 \\ Bach Xuan Tran ${ }^{7,8}$ \\ Huyen Thi Thanh $\mathrm{Vu}\left(\mathbb{D}^{1,3}\right.$ \\ Carl A Latkin (D) ${ }^{8}$ \\ Cyrus $\mathrm{SH} \mathrm{Ho}{ }^{9}$ \\ Roger CM Ho $\mathbb{D}^{6,10}$
}

'Scientific Research Department, National Geriatric Hospital, Hanoi,

Vietnam; ${ }^{2}$ Dinh Tien Hoang Institute of Medicine, Hanoi, Vietnam; ${ }^{3}$ Department of Gerontology, Hanoi Medical University, Hanoi, Vietnam; ${ }^{4}$ Institute for Global Health Innovations, Duy Tan University, Da Nang, Vietnam; ${ }^{5}$ Center of Excellence in Evidence-based Medicine, Nguyen Tat Thanh University, Ho Chi Minh City, Vietnam; ${ }^{6}$ Center of Excellence in Behavioral Medicine, Nguyen Tat Thanh University, Ho Chi Minh City, Vietnam; ${ }^{7}$ Institute for Preventive Medicine and Public Health, Hanoi Medical University, Hanoi, Vietnam; ${ }^{8}$ Johns Hopkins Bloomberg School of Public Health, Baltimore, MD, USA; ${ }^{9}$ Department of Psychological Medicine, National University Hospital, Singapore; ${ }^{10}$ Department of Psychological Medicine, Yong Loo Lin School of Medicine, National University of Singapore, Singapore

Correspondence: Thu Thi Hoai Nguyen National Geriatric Hospital, IA Phuong Mai, Hanoi 100000 , Vietnam

$\mathrm{Tel}+84962841944$

Email nththu.bvlk@gmail.com
Purpose and aim: The activity center (AC), an effective model for health support and health-related quality of life improvements for older people, has been operating for many years worldwide. This study aimed to assess the necessity of and preference for attending AC and its desired functions and facilities in elderly people in Vietnam.

Subjects and methods: A cross-sectional study was conducted at parks and senior clubs, with 121 participants from 6 February to 20 April 2017, in Hanoi. The health status, preference, and willingness-to-pay for AC use of respondents were assessed.

Results: Over $75 \%$ of respondents agreed to establish an AC for older people. Among them, approximately $71.7 \%$ were willing to pay a monthly fee for this center. Elderly individuals who obtain regular physical examination when feeling pain/discomfort and who were participating in clubs for elder people were more likely to agree to establish and pay for an AC. Meanwhile, women who have to take care of grandchildren, people who were saving money and people who had children working in organizations or who were freelancers were less likely to agree to establish and pay for AC.

Conclusion: The results suggest the feasibility of establishment of ACs in Vietnam, with a high proportion of participants agreeing to such establishing and willing to pay for the AC.

Keywords: activity center, older people, elderly, Vietnam

\section{Introduction}

Vietnam's population will enter the "aged phase" in the next two decades when its aging index rises from 35.5 in 2009 to more than 100 in 2032. ${ }^{1,2}$ In 2008, the total number of seniors in Vietnam amounted to 9.47 million, an estimated $11 \%$ of the total population. ${ }^{1}$ Besides this, by 2020 , more than 12 million people in Vietnam will be counted as seniors. ${ }^{3}$ However, the health care system of Vietnam offers very few services or facilities that focus on and promote health-related quality of life of the elderly, which, in turn, increases life expectancy. ${ }^{1,4}$

The first activity center (AC) was established in New York City in $1943 .{ }^{5}$ The AC is a great model for seniors who are retired, weak, living alone or who have free time to maintain mental and physical functions. The AC or daily care center is a facility that provides comprehensive health care programs for the elderly. ${ }^{6}$ It operates during daytime from Monday to Friday. Each month, there are many designed schedules that include activities or programs to promote physical and mental health. ${ }^{7}$ Ideally, an AC consists of many motor function and skill rooms, such as a gym, a library, a kitchen, a creative room or dance room. There are also specialized and trained staff on-site, 
such as nurses, physiotherapists, occupational therapists, nutritionists and volunteers. They collaborate to develop useful programs and to improve the mobility and social skills of participants. ${ }^{5,7}$ Potentially, AC participation may lower the risk of disease-related disability. In one AC study, approximately $90 \%$ of participants reported their well-being to be the same or better than a few years previously. ${ }^{5}$ Some ASEAN countries such as Singapore, ${ }^{8}$ Malaysia ${ }^{9}$ and the Philippines ${ }^{10}$ have started establishing ACs for seniors. The establishment of AC is a health service that can bring good and comfortable caring to the older population. ${ }^{5,11}$

Despite the evidence-based success stories of ACs, Vietnam has not adopted ACs. Additionally, Hanoi is the capital of Vietnam and a huge population lives here. Thus, this research was conducted to investigate the preference of establishing an AC for the elderly in Hanoi and to evaluate the factors associated with the preference of establishing an AC.

\section{Subjects and methods Subjects}

People were interviewed if they met the following criteria: 1) over 60 years old; 2) live in Hanoi; and 3) accept to take part in the study. Those who were 1) under 60 years old; 2) had mental disorders; and 3) unable to join in this study were excluded from it.

\section{Study design and sample}

A cross-sectional study was performed, and the pool of subjects was chosen by a convenience sampling method. We approached the elderly who spend free time at the parks or senior clubs in the center of Hanoi from 6 February to 20 April 2017 and invited them to take part in the study. To prevent selection bias, we repeated the questionnaire three times then chose the answer that was repeated twice or more. Of 130 subjects, there were 121 eligible participants, and 9 people were excluded because they were under 60 years old. The 45-item questionnaire was constructed to measure demographic characteristics, daily activities, and common older people's hobbies, activities of daily living (ADL), instrumental activities of daily living (IADL) ${ }^{12}$ and Mini Nutritional Assessment Short Form. ${ }^{13}$ Mini-Cog ${ }^{14}$ was used to assess cognitive impairment.

\section{Variables and data processing}

The questionnaires were translated into Vietnamese by two translators and back-translation was done by a native
English speaker and piloted in ten people. The participants were interviewed for 20-30 mins. In the questionnaire, the collected personal data of participants consisted of age (years), gender (male, female), educational attainment (illiterate, primary school, secondary school or higher level), marital status, living status (living with children, taking care of grandchildren), family, income status (dependence on children, have been working, saving money or monthly pension) and health condition (frequency for check-up, frequency of examinations, common diseases).

The common activities used to survey the participants included playing sports, doing exercise, dancing, doing yoga, going to picnics, listening to music, chatting, traveling, doing volunteer work, eating, playing musical instruments, playing chess, reading books and watching TV. These items used a 4-point scale to assess the preference of interviewees for each activity (1: dislike; 2: normal; 3 : like; 4: strongly like). Then, answers like and strongly like were put in the preferred group to find out suitable programs for $\mathrm{AC}$ and to analyze factors associated with the preference for popular activities.

The preference for the establishment of an AC was defined by "Yes" or "No" answers to "Do you want to join this activity center if it were to open" after they listened to a description of AC programs. The item "how much time

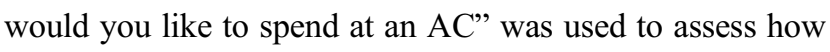
older people might spend time at an AC per week. There were five questions that explored willingness-to-pay for $\mathrm{AC}$ memberships including: "Would you be willing to pay a monthly fee for AC?", “would you pay 200.000VND per month", "would you pay 500.000VND per month", "would you pay $800.000 \mathrm{VND}$ per month" and "What is the highest amount would you pay?" (1 USD=22,500 VND in 2017). To analyze factors associated with agreeing to establish AC and willingness- to-pay for AC, the variables were chosen to put in the multivariate model including: taking care of grandchildren, gender, education attainment, income status, children occupation, working in organizations or freelancer, frequency of health check-ups, feeling pain or discomfort, participate in elderly clubs, frequency of exercise and IADL score. These variables often happen and meet in the daily life of elderly people.

\section{Process of data analysis}

After collecting data, information was coded and entered to Epidata 3.1 software then analyzed and processed by Stata 12.0 software. Statistical significance was presented with $p$-value which is $<0.05$. Descriptive statistics 
(frequency) were used to present demographic information. Multivariate logistic regression combined with stepwise backward selection strategies (with the $p$-value $<0.2$ of the likelihood as a threshold to select the variables).

\section{Ethical consideration}

The study was approved by the National Geriatric Hospital Research Ethics Committee (No. 81 NGH IRB). The purposes of the study were explained to eligible patients and they participated voluntarily in the research. Verbal informed consent was acceptable and approved by the National Geriatric Hospital Research Ethics Committee.

\section{Results}

Table 1 describes the demographic characteristics of the study population. $55.4 \%$ of participants $(n=67)$ were female, and the ratio of female to male was $1: 2.4$. The majority of participants $(48.8 \%)$ were between 60 and 70 years old, followed by the age group of 71-80. More than half of the participants had obtained post-secondary school level education and had a monthly pension. Moreover, the majority of participants were overweight, reported health check-ups more than twice a year and exercised daily. In addition, most of the participants $(71.9 \%)$ lived with children, and $31.9 \%$ reported taking care of grandchildren.

The percentage of participants who favor AC establishment and are willingness-to-pay for AC membership is allocated in Table 2. $77.5 \%(n=93)$ of participants favored AC establishment, and $71.7 \%$ of those were willing to pay a monthly membership fee. In addition, $50 \%$ of people would be willing to pay over 500.000 VND per month. The majority of participants would be willing to spend 1-8 hrs a week at the AC.

Table 3 presents the percentage of preference level for popular activities. Watching $\mathrm{TV}$, traveling and reading books or newspapers are the most favorable activities. On the other hand, yoga, playing chess and dancing were not viewed as favorable.

Table 4 shows that there was no difference in the agreement of establishing an AC by gender, age, educational attainment, income status, ADL score and IADL score. However, the proportion of people who were widowed and favored the establishment of an $\mathrm{AC}$ $(21.5 \%)$ were lower than who living with a spouse. In addition, participants who were in elderly clubs showed strong agreement to establish an AC.

Factors associated with agreeing to establish AC and willingness-to-pay for $\mathrm{AC}$ are described in Table 5. The results
Table I Demographic characteristics of patients $(n=|2|)$

\begin{tabular}{|c|c|c|}
\hline Characteristics & $\begin{array}{l}\text { Frequency } \\
(n=|2|)\end{array}$ & Percentage \\
\hline \multicolumn{3}{|l|}{ Gender } \\
\hline Male & 54 & 44.6 \\
\hline Female & 67 & 55.4 \\
\hline \multicolumn{3}{|l|}{ Age groups } \\
\hline $60-70$ & 59 & 48.8 \\
\hline $71-80$ & 41 & 33.9 \\
\hline $81-90$ & 19 & 15.6 \\
\hline$>90$ & 2 & 1.7 \\
\hline \multicolumn{3}{|l|}{ Educational attainment } \\
\hline Illiterate & 7 & 5.8 \\
\hline Primary school & 17 & 14.1 \\
\hline Secondary school & 28 & 23.1 \\
\hline >High school & 69 & 57.0 \\
\hline \multicolumn{3}{|l|}{ Income status } \\
\hline Depend on children & 31 & 25.6 \\
\hline working & 16 & 13.2 \\
\hline savings & 11 & 9.1 \\
\hline Monthly pension & 63 & 52.1 \\
\hline \multicolumn{3}{|l|}{ BMI group } \\
\hline Underweight & 3 & 2.5 \\
\hline Normal & 58 & 47.9 \\
\hline Overweight/obesity & 60 & 49.6 \\
\hline \multicolumn{3}{|l|}{ Living with children } \\
\hline Yes & 87 & 71.9 \\
\hline No & 34 & 28.1 \\
\hline \multicolumn{3}{|l|}{ Taking care of grandchildren } \\
\hline Yes & 37 & 31.9 \\
\hline No & 79 & 68.1 \\
\hline \multicolumn{3}{|l|}{ Frequency of health check-ups } \\
\hline Never & 5 & 4.1 \\
\hline Feel pain or discomfort & 38 & 31.4 \\
\hline Several years & 4 & 3.3 \\
\hline More than twice per year & 74 & 61.2 \\
\hline \multicolumn{3}{|l|}{ Frequency of doing exercise } \\
\hline Never & 8 & 6.6 \\
\hline Rarely, few times per month & 8 & 6.6 \\
\hline Few times per week & 15 & 12.4 \\
\hline Every day & 90 & 74.4 \\
\hline
\end{tabular}

Abbreviation: BMI, body mass index.

showed that those who were female $(\mathrm{OR}=0.38,95 \% \mathrm{CI}: 0.15-$ 0.98); had to take care of their grandchildren $(\mathrm{OR}=0.36,95 \%$ CI: $0.11-1.19$ and $\mathrm{OR}=0.19,95 \%$ CI: $0.07-0.53)$; had savings $(\mathrm{OR}=0.16,95 \% \mathrm{CI}: 0.02-1.05)$; and had children working in organizations or freelancer $(\mathrm{OR}=0.22,95 \% \mathrm{CI}$ : $0.05-1.01)$ were less likely to agree to establish and pay for AC. On the 
Table 2 The percentage of participants agreeing to establish an $A C$ and pay monthly fees

\begin{tabular}{|l|l|l|}
\hline Characteristics & $\begin{array}{l}\text { Frequency } \\
\text { (n) }\end{array}$ & $\begin{array}{l}\text { Percentage } \\
\text { (\%) }\end{array}$ \\
\hline $\begin{array}{l}\text { Establish an AC } \\
\text { Yes }\end{array}$ & 93 & \\
No & 28 & 77.5 \\
\hline Pay monthly fees & & 22.5 \\
Yes & 66 & \\
No & 26 & 71.7 \\
\hline Amount of payment to & & 28.3 \\
participate in AC & & \\
$\geq 500.000$ VND & 14 & 50 \\
$<500.000$ VND & 14 & 50 \\
\hline Time spending at AC & & \\
I-8 hrs per week & 54 & 58.1 \\
$>8$ hrs per week & 39 & 41.9 \\
\hline
\end{tabular}

Abbreviation: AC, activity center.

other hand, people who engage in regular physical examination when feeling pain or discomfort $(\mathrm{OR}=10.28,95 \% \mathrm{CI}$ : $2.06-51.35)$ and have joined elderly clubs ( $\mathrm{OR}=9.95 ; 95 \% \mathrm{CI}$ : 2.95-33.64 and $\mathrm{OR}=6.67,95 \%$ CI: $2.35-18.88$ ) were more likely to agree to establish and pay for AC as compared to their counterparts.

\section{Discussion}

The findings indicate that the elderly preferred establishing an AC in Hanoi and were willing to pay a fee for participation. Moreover, many of the older persons wanted to read books, watch TV at the AC and travel with others.
The study found that seniors in Hanoi frequently visited doctors for a check-up, which is an indication that they are concerned about their health. Those who had a monthly pension might be financially independent. The main difference between a European family and a Vietnamese family is the number of generations living together. ${ }^{15}$ In Vietnam, children and grandchildren are responsible for taking care of their parents. ${ }^{16}$ Participants who did not need to take care of their children daily are likely to have more free time to be involved in social events or to enjoy their hobbies at ACs.

Additionally, we found that the overweight population has increased. ${ }^{17}$ Our results also highlight the preference for exercising among the elderly which suggests that it would be beneficial to have a gym in an AC. Exercising can help to control weight and lower the risks of cardiovascular diseases. However, the risks of falling and other exercise-related problems should be taken into consideration when building a gym for the older adults. ${ }^{18}$ The gym should avoid heavy workout machines and should be managed by physiotherapists or occupational therapists. It may be also beneficial for participants to have a nutritionist at the $\mathrm{AC}$ to improve their nutritional knowledge and to help plan meals for the elderly. In the study of Le Van Hoi, ${ }^{19}$ it was found that the number of people who want to use a nursing center was the lowest percentage. Otherwise, households are willing to pay for nursing and day care centers more than the older persons are. There are some limitations of this study which include the implementation programs, mobile teams and community-centric areas which are rare in Vietnam and some methodological problems. ${ }^{19}$

Table 3 Percentage of preference's level with popular activities

\begin{tabular}{|l|l|l|l|l|l|l|l|l|}
\hline \multirow{2}{*}{ Activities } & \multicolumn{2}{l}{ Dislike } & \multicolumn{2}{l|}{ Normal } & \multicolumn{2}{l|}{ Like } & \multicolumn{2}{l|}{ Extremely like } \\
\cline { 2 - 9 } & $\mathbf{n}$ & $\%$ & $\mathbf{n}$ & $\%$ & $\mathbf{n}$ & $\%$ & $\mathbf{n}$ & $\%$ \\
\hline Playing sports & 60 & 49.5 & 10 & 8.3 & 17 & 14 & 34 & 28.1 \\
Dance & 28 & 59.6 & 2 & 4.2 & 4 & 8.5 & 13 & 27.7 \\
Yoga & 33 & 68.8 & 1 & 2.1 & 0 & 0 & 14 & 29.2 \\
Traveling & 30 & 25 & 13 & 10.8 & 36 & 30 & 41 & 34.2 \\
Sing folk music & 46 & 38 & 15 & 12.4 & 25 & 20.7 & 35 & 28.9 \\
Chatting & 18 & 14.9 & 23 & 19 & 54 & 44.6 & 26 & 21.5 \\
Volunteer & 20 & 16.7 & 22 & 18.3 & 41 & 34.2 & 37 & 30.8 \\
Eating with friend & 35 & 29.2 & 24 & 20 & 36 & 30 & 25 & 20.8 \\
Playing musical instrument & 15 & 30.6 & 8 & 16.3 & 10 & 20.4 & 16 & 32.7 \\
Playing chess, cards & 73 & 61.3 & 8 & 6.7 & 10 & 8.4 & 28 \\
Reading book, newspaper & 29 & 25 & 11 & 9.5 & 26 & 22.4 & 50 \\
Watching television & 1 & 2.1 & 2 & 4.2 & 6 & 12.5 & 39 \\
\hline
\end{tabular}


Table 4 Characteristics of respondents agreeing and not agreeing to establish ACs

\begin{tabular}{|c|c|c|c|c|c|c|c|}
\hline \multirow[t]{3}{*}{ Characteristics } & \multicolumn{7}{|c|}{ Agree to establish an AC } \\
\hline & \multicolumn{2}{|c|}{ Yes } & \multicolumn{2}{|c|}{ No } & \multicolumn{2}{|c|}{ Total } & \multirow[t]{2}{*}{$p$-Value } \\
\hline & $\mathbf{n}$ & $\%$ & $\mathbf{n}$ & $\%$ & $\mathbf{n}$ & $\%$ & \\
\hline \multicolumn{8}{|l|}{ Gender } \\
\hline Male & 40 & 43.0 & 14 & 50.0 & 54 & 44.6 & 0.51 \\
\hline Female & 53 & 57.0 & 14 & 50.0 & 67 & 55.4 & \\
\hline \multicolumn{8}{|l|}{ Age group } \\
\hline $60-70$ & 46 & 49.5 & 13 & 46.4 & 59 & 48.8 & 0.67 \\
\hline $7 I-80$ & 29 & 31.2 & 12 & 42.9 & 41 & 33.9 & \\
\hline $8 I-90$ & 16 & 17.2 & 3 & 10.7 & 19 & 15.7 & \\
\hline$>90$ & 2 & 2.2 & 0 & 0.0 & 2 & 1.7 & \\
\hline \multicolumn{8}{|l|}{ Educational attainment } \\
\hline Illiterate & 6 & 6.5 & I & 3.6 & 7 & 5.8 & 0.81 \\
\hline Primary school & 14 & 15.1 & 3 & 10.7 & 17 & 14.1 & \\
\hline Secondary school & 22 & 23.7 & 6 & 21.4 & 28 & 23.1 & \\
\hline$\geq$ High school & 51 & 54.8 & 18 & 26.3 & 69 & 57.0 & \\
\hline \multicolumn{8}{|l|}{ Income status } \\
\hline Depend on children & 23 & 24.7 & 8 & 28.6 & 31 & 25.6 & 0.35 \\
\hline Working & 15 & 16.1 & I & 3.6 & 16 & 13.2 & \\
\hline Savings & 9 & 9.7 & 2 & 7.1 & 11 & 9.1 & \\
\hline Monthly pension & 46 & 49.5 & 17 & 60.7 & 63 & 52.1 & \\
\hline \multicolumn{8}{|l|}{ Marital status } \\
\hline Widowed & 20 & 21.5 & 14 & 50.0 & 34 & 28.1 & 0.02 \\
\hline Divorced & 4 & 4.3 & 1 & 3.6 & 5 & 4.1 & \\
\hline Live with spouse & 59 & 63.4 & 13 & 46.4 & 72 & 59.5 & \\
\hline Separated & 10 & 10.8 & 0 & 0.0 & 10 & 8.3 & \\
\hline \multicolumn{8}{|l|}{ ADL score } \\
\hline 6 & 17 & 18.3 & 2 & 7.1 & 19 & 15.7 & 0.24 \\
\hline$<6$ & 76 & 81.7 & 26 & 92.9 & 102 & 84.3 & \\
\hline \multicolumn{8}{|l|}{ IADL score } \\
\hline 8 & 17 & 18.3 & 4 & 14.3 & 21 & 17.4 & 0.78 \\
\hline$<8$ & 76 & 81.7 & 24 & 85.7 & 100 & 82.6 & \\
\hline \multicolumn{8}{|l|}{ Occupation of children } \\
\hline Farmer, unstable and unemployed & 18 & 20.5 & 3 & 10.7 & 21 & 18.1 & 0.24 \\
\hline Work in government, personnel or staff & 10 & 11.4 & I & 3.6 & 11 & 9.5 & \\
\hline Business & 11 & 12.5 & 2 & 7.1 & 13 & 11.2 & \\
\hline Work organizations or freelancer & 49 & 55.7 & 22 & 78.6 & 71 & 61.2 & \\
\hline \multicolumn{8}{|l|}{ Join in elderly clubs } \\
\hline No & 32 & 34.8 & 21 & 75.0 & 53 & 44.2 & $p<0.01$ \\
\hline Yes & 60 & 65.2 & 7 & 25.0 & 67 & 55.8 & \\
\hline
\end{tabular}

Abbreviations: AC, activity center; ADL, activities of daily living; IADL, instrumental activities of daily living.

Potentially, the AC could provide both physical and mental support for the seniors. ${ }^{20}$ We have acknowledged the advantages of nursing homes like the personalized health care services offered to older people and disadvantages, such as increasing sense of isolation and loneliness, losing freedom and reducing proximity to family. ${ }^{21}$ The AC allows participants to maintain family bonding unlike in nursing homes. The AC would open 
Table 5 Factors associated with agreeing to establish AC and willingness-to-pay for AC

\begin{tabular}{|c|c|c|c|c|}
\hline \multirow[t]{2}{*}{ Characteristics } & \multicolumn{2}{|c|}{ Agree to establish to $A C$} & \multicolumn{2}{|c|}{ Willingness-to-pay for $A C$} \\
\hline & OR & $95 \% \mathrm{Cl}$ & OR & $95 \% \mathrm{Cl}$ \\
\hline $\begin{array}{l}\text { Take care of grandchildren (yes vs no) } \\
\text { Gender (male - ref) } \\
\text { Female }\end{array}$ & $0.36^{*}$ & $0.11 ; 1.19$ & $\begin{array}{l}0.19^{* * *} \\
0.38^{* *}\end{array}$ & $\begin{array}{l}0.07 ; 0.53 \\
0.15 ; 0.98\end{array}$ \\
\hline $\begin{array}{l}\text { Education attainment (illiterate - ref) } \\
\text { Secondary school }\end{array}$ & 0.32 & $0.07 ; 1.53$ & & \\
\hline $\begin{array}{l}\text { Income status (depend on children - ref) } \\
\text { Have savings }\end{array}$ & & & $0.16 *$ & $0.02 ; 1.05$ \\
\hline $\begin{array}{l}\text { Children occupation (farmer, unstable and unemployed - ref) } \\
\text { Working in organizations or freelancer }\end{array}$ & $0.22 *$ & $0.05 ; 1.01$ & & \\
\hline $\begin{array}{l}\text { Frequency of health check-ups (never - ref) } \\
\text { Feel pain or discomfort } \\
\text { Participate in elderly clubs (yes vs no) }\end{array}$ & $\begin{array}{l}10.28 * * * \\
9.95^{* * * *}\end{array}$ & $\begin{array}{l}2.06 ; 51.35 \\
2.95 ; 33.64\end{array}$ & $6.67^{* * *}$ & $2.35 ; 18.88$ \\
\hline $\begin{array}{l}\text { Frequency of exercise (never - ref) } \\
\text { Few times per month } \\
\text { IADL score }\end{array}$ & 5.44 & $0.64 ; 46.19$ & 1.33 & $0.92 ; 1.91$ \\
\hline
\end{tabular}

Notes: $* * * P<0.01$, ** $P<0.05$, $* P<0.1$.

Abbreviations: AC, activity center; IADL, instrumental activities of daily lliving.

from Monday to Friday; hence, the participants still spend Saturday and Sunday with their children instead of staying at nursing homes all the time. Moreover, the AC provides health care and social programs that are designed by doctors, nurses, physiotherapists, occupational therapists or nutritionists. ${ }^{5,6}$ It might be more tailored to the elderly than a regular club or social organization. Each week, the participants first view the schedule and then register for the event(s) of interest. But it is important to have physiotherapists and occupational therapists. They support and play important roles in brain function and mobility of older people. ${ }^{22}$

Our results also suggest activities such as watching TV, reading books or magazines and traveling are most favored. In the questionnaire we used 4-point scale because of in view of seniors' characteristics, it is better that they answer in exact words instead of giving numbers which could confuse participants. Therefore, establishing a library or a cozy living room, and organizing some short trips to rural areas would encourage the elderly to come to the AC. On the other hand, dancing reduces the risk of falling in community dwellings for older adults. ${ }^{23}$ In addition, doing community volunteer work, such as at handicap centers in Hanoi or poor areas, could be arranged several times a month. According to one study, ${ }^{24}$ the number of hours spent volunteering decreased the risk of hypertension and increased the well-being of elderly people. Thus, some cultural and religious activities should be incorporated into daily activities at the AC.

The study results suggest that participants with children who have good and stable occupations were most interested in joining an AC. Therefore, this finding suggests that older people who have children with good economic standing and occupations probably have sufficient free time to take part in $\mathrm{AC}$ and social activities. ${ }^{25}$ As the number of people living alone is increasing typically in urban areas, ${ }^{26}$ it will be beneficial to have an AC for those people.

On the other hand, this study also showed the relationship between age, sex, educational level, income status, living with children, taking care of grandchildren, ADL, IADL and wanting to join an AC. We found that participants who have a higher functional level and independence of income are more likely to value the establishment of an AC. Participants who had normal ADL and IADL ranges were more interested in joining an AC. Deterrents to joining an $\mathrm{AC}$ include weakness, retirement, not working, living alone, dependence and having free time. People with dementia or cognitive impairment would need special services that may not be available at an $\mathrm{AC}^{4}$ 
This is the first study in Vietnam to measure preference for the establishment of an AC for the elderly. Because of the purposes of this study were preference and willing to pay for establishing ACs; thus, we did not expect the neutral answer from respondents then we used 4-point scale and yes/no questions. On the other hand, this scale and question were simple and suitable for older adults. There are certain limitations when interpreting the results. The population studied was limited to urban seniors, which limits the ability to generalize the result. Future studies would need to consider geographic distribution and cultural representation. Moreover, the study was limited to descriptive analysis and did not provide an in-depth assessment of factors associated with the preference and willingness-to-pay for the service.

\section{Conclusion}

The study demonstrated the favorable attitude toward the establishment of an AC among elderly people in Hanoi and a willingness-to-pay a membership fee. In Vietnam, research and policies on the elderly are beginning to pay attention to the health-related quality of life and health considerations. Thus, an AC is a place which can create an environment for the elderly to improve their physical, mental and emotional health by socializing with others and participating in various activities. Our findings provide guidelines for caregivers to operate an $\mathrm{AC}$ and develop programs to offer good quality and professional health service to the older population.

\section{Acknowledgment}

The authors would like to thank the teachers working at Hanoi Medical University and family and friends who had useful advice to help us complete this study.

\section{Disclosure}

Carl A Latkin reports grants from the US NIH, during the conduct of the study. The authors report no other conflicts of interest in this work.

\section{References}

1. Long GT. The aging Population in Viet Nam Current status, Prognosis, and Possible Policy Responses. UNFPA; 2011.

2. The World Bank. Live Long and Prosper Aging in East Asia and Pacific. Washington, USA; 2016.

3. Binh NT. Elderly people in Vietnam at present time. Int J Soc Sci Educ. 2012;2(3):276-282.

4. Kruk MEFL. Assessing health system performance in developing countries: a review of the literature. Health Policy. 2008;85(260-80):263-276. doi:10.1016/j.healthpol.2007.09.003
5. Aday RH. The Evolving Role of Senior Centers in the 21st Century. Murfreesboro: Senate Special committee on Aging; 2003. TN 371322003.

6. Lawrence Robinson JS, Ph D Adult Day Care Services Finding the Best Center for your Needs. Available from: https://www.helpguide.org/arti cles/caregiving/adult-day-care-services. Accessed March 20, 2019.

7. Schulz E. The Long-term Care System for the Elderly in Denmark. 2010. Available from: https://www.ceps.eu/ceps-publications/long-term-caresystem-elderly-denmark/. Accessed March 20, 2019.

8. Ministry of social and family develoment, Singapore Government. Services and Programmes For Elderly. Available from: https://www. msf.gov.sg/policies/Helping-the-Needy-and-Vulnerable/SupportingVulnerable-Elderly/Pages/Services-and-Programmes-for-Elderly. aspx. Accessed August 10, 2016.

9. Akil SM, Abdullah S, Sipon S. Challenges in managing elderly care centres in Malaysia. Int J Arts Sci. 2014;7(3):129.

10. INQUIRER.NET. Senior Hub: an Ideal Place where Seniors can Spend their Leisure Time; 2014; Available from: http://lifestyle. inquirer.net/178455/senior-hub-an-ideal-place-where-seniors-canspend-their-leisure-time/. Accessed March 20, 2017.

11. Harris-Kojoin L, Sengupta M, Park-Lee E, et al. Long-term care providers and services users in the United States: data from the national study of long-term care provider. National Cent Health Stat. 2013-2014;3(38):2016.

12. Marie Boltz SAG. Katz Index of Independence in Activities of Daily Living (ADL) and the lawton Instrumental Activities of Daily Living (IADL) scale. Best Pract Nurs Care Older Adults. 2007;2(3):204-212.

13. Vellas B, Villars H, Abellan G, et al. Overview of the MNA - its history and challenges. J Nutr Health Aging. 2006;10(6):456-465.

14. Borson SSJ, Chen PJ. The mini-cog as a screen for dementia: validation in a population-based sample. $J$ Am Geriatr Soc. 2003;51 (10):1451-1454. doi:10.1046/j.1532-5415.2003.51465.x

15. Ngoc TTB, Barysheva GA, Shpekht LS. The care of elderly people in Vietnam. EpSBS. 2015;2357. Available from: http://www.futureacad emy.org.uk/files/images/upload/63-WELLSO.pdf. Accessed August 20,2018

16. Hoi LV, Thang P, Lindholm. L. Elderly care in daily living in rural Vietnam: need and its socioeconomic determinants. BMC Geriatr. 2011;11(81). doi:10.1186/1471-2318-11-81

17. Walls HL, Peeters A, Son PT, et al. Prevalence of underweight, overweight and obesity in urban Hanoi, Vietnam. Asia Pac J Clin Nutr. 2009;18(2):234-239.

18. Talbot Rice H, Malcolm L, Norman K, et al. An evaluation of the St christopher's hospice rehabilitation gym circuits classes: patient uptake, outcomes, and feedback. Prog Palliat Care. 2014;22 (6):319-325. doi:10.1179/1743291X14Y.0000000083

19. Tien NT, Van Tien N, Van Dung D, Chuc NT, Sahlen KG, Lindholm L. Willingness to use and pay for options of care for communitydwelling older people in rural Vietnam. BMC Health Serv Res. 2012;12:36. doi:10.1186/1472-6963-12-36

20. Lim KTL. Factors associated with physical activity among older people-a population-based study. Prev Med. 2005;40(1):33-40. doi:10.1016/j.ypmed.2004.04.046

21. Woo J, Goggins W, Sham A, Ho SC. Public health significance of the frailty index. Disabil Rehabil. 2006;2006(28):515-521. doi:10.1080/ 09638280500215867

22. Munce SE, Graham ID, Salbach NM, et al. Perspectives of health care professionals on the facilitators and barriers to the implementation of a stroke rehabilitation guidelines cluster randomized controlled trial. BMC Health Serv Res. 2017;17:440. doi:10.1186/s12913-017-2389-7

23. Britten L, Addington C, Astill S. Dancing in time: feasibility and acceptability of a contemporary dance programme to modify risk factors for falling in community dwelling older adults. $B M C$ Geriatr. 2017;17(1):83. doi:10.1186/s12877-017-0515-3

24. Sneed RSCS. A prospective study of volunteerism and hypertension risk in older adults. Psychol Aging. 2013;28(2):578-586. doi:10.1037/ a0032718 
25. Ron Goeree VD. Introduction to health economics and decisionmaking: is economics relevant for the frontline clinician? Clin Gastroenterol. 2013;27(6):831-844. doi:10.1016/j. bpg.2013.08.016
26. Long GT, Pfau WD, editors. The elderly population in vietnam during economic transformation: an overview. In: Social Issues Under Economic Transformation and Integration in Vietnam. Hanoi: Vietnam; 2007:185-210.

\section{Publish your work in this journal}

The Journal of Multidisciplinary Healthcare is an international, peerreviewed open-access journal that aims to represent and publish research in healthcare areas delivered by practitioners of different disciplines. This includes studies and reviews conducted by multidisciplinary teams as well as research which evaluates the results or conduct of such teams or healthcare processes in general. The journal covers a very wide range of areas and welcomes submissions from practitioners at all levels, from all over the world. The manuscript management system is completely online and includes a very quick and fair peer-review system. Visit http://www.dovepress.com/testimonials. php to read real quotes from published authors. 